\title{
Severe infection increases cardiovascular risk among HIV-infected individuals
}

\author{
Emersom Cicilini Mesquita ${ }^{1} \mathbb{D}$, Lara Esteves Coelho², Rodrigo Teixeira Amancio', Valdilea Veloso², \\ Beatriz Grinsztejn², Paula Luz ${ }^{2}$ and Fernando Augusto Bozza ${ }^{1,3 *}$
}

\begin{abstract}
Background: The identification and management of cardiovascular risk factors became a major clinical issue among HIV-infected individuals in the post-cART era. As in the past decades the link between acute infections and cardiovascular diseases became clear in the general population, we sorted to investigate the role of severe infections on incident cardiovascular diseases (CVDs) among HIV-infected individuals.

Methods: HIV-infected individuals aged $\geq 18$ years, with no history of CVD were followed from January 2000 to December 2013 until the occurrence of the first CVD event, death or end of study, whichever occurred first. To explore the effect of severe infections on the incidence of CVD we used extended Cox regression models and stratified posthospitalization follow-up time into three periods: < 3 months, 3-12 months and $>12$ months post discharge.

Results: One hundred-eighty four persons from $3384 \mathrm{HIV}$-infected individuals developed incident CVD events during the follow-up (incidence rate $=11.10 / 1000$ PY (95\%Cl: 9.60-12.82)). Risk of an incident CVD was 4-fold higher at $<3$ months post-hospitalization for severe infections (adjusted hazard ratio [aHR], 4.52; 95\% confidence interval [Cl] 2.46-8.30), after adjusting for sociodemographic and clinical factors as well as comorbidities. This risk remained significant up to one year (3-12 months post hospital discharge aHR 2.39, 95\% Cl 1.30-4.38). Additionally, non-white race/ethnicity (aHR 1.49, 95\% Cl 1.10-2.02), age $\geq 60$ years (aHR 2.01,95\% Cl 1.01-3.97) and hypertension (aHR 1.90, 95\% Cl 1.38-2.60) were associated with an increased risk of CVD events. High CD4 ( $\geq 500$ cells $/ \mathrm{mm}^{3}$ : aHR $0.41,95 \% \mathrm{Cl} 0.27-0.62$ ) and cART use (aHR 0.21, 95\% Cl 0.14-0.31) reduced the risk of CVD events.
\end{abstract}

Conclusions: We provide evidence for a time-dependent association between severe infection and incident cardiovascular disease in HIV-infected individuals. CART use, and high CD4 count were significantly associated with reduced hazards of CVD.

Keywords: Cardiovascular disease, Risk factor, HIV, AIDS, Severe infection, CART, CD4+

\section{Background}

With introduction and widespread use of combined antiretroviral therapy (cART) a marked shift in causes of hospitalizations and deaths have been observed among HIV-infected individuals, with a relative increase in non-communicable diseases (NCD) and non-AIDS-defining infections [1-3]. Among NCD, cardiovascular diseases (CVD) represent a major challenge. HIV-infected individuals have a higher risk for CVD such as myocardial infarction (MI),

\footnotetext{
* Correspondence: bozza.fernando@gmail.com

'Laboratório de Pesquisa Clínica em Medicina Intensiva, Instituto Nacional de Infectologia Evandro Chagas (INI), Fundação Oswaldo Cruz (FIOCRUZ), Rio de Janeiro, Brazil

${ }^{3}$ Instituto D'Or de Pesquisa e Ensino (IDOR), Rio de Janeiro, Brazil

Full list of author information is available at the end of the article
}

stroke, heart failure, and sudden cardiac death [4-7]. Although a higher burden of traditional CVD risk factors have been reported in HIV-infected individuals [8, 9], an elevated risk remains even after adjusting for these factors [10, 11]. Additionally, chronic exposure to cART [12, 13], HIV infection itself, and HIV-specific clinical parameters, such as detectable HIV-1 RNA, and nadir CD4+ count $\leq 50$ cells $/ \mathrm{mm}^{3}$, may also contribute to this increased CVD risk [14, 15].

As AIDS became a chronic condition [16], non-AIDS, life-threatening bacterial infection and sepsis grew as cause of hospitalization in this population [17]. In the intensive care scenario, sepsis is the major determinant of outcome in HIV-infected individuals [18, 19]. Interestingly, despite the presence of severe immunosuppression,

(c) The Author(s). 2019 Open Access This article is distributed under the terms of the Creative Commons Attribution 4.0 International License (http://creativecommons.org/licenses/by/4.0/), which permits unrestricted use, distribution, and 
a robust innate immune response is present and associated with hospital mortality [20]. In this study, we hypothesized that HIV-infected individuals who were hospitalized for severe infections would have an increased CVD risk compared to HIV-infected individuals without hospitalization for severe infections. Identifying specific CVD risk in this population is critical for guiding targeted CVD prevention and treatment.

\section{Methods}

\section{Data sources and study population}

The Instituto Nacional de Infectologia Evandro Chagas (INI, formerly known as Instituto de Pesquisa Clínica Evandro Chagas/IPEC) provides primary and specialized health care for HIV-infected individuals in Rio de Janeiro State, Brazil. It comprises an outpatient clinic, emergency department and inpatient care, including an intensive care unit. All health care services provided by INI are funded by Brazilian's public health system (known as Sistema Único de Saúde, SUS). A longitudinal observational cohort including socio-demographic, laboratory and clinical data has been maintained at INI since 1998. Data of patients receiving primary care at INI is abstracted from medical records and is updated periodically by trained staff. Cohort procedures have been described and results published [3, 21, 22].

For this study, from January 12,000 until December 312,013, we included HIV-infected individuals aged 18 years old or older, who were followed in the cohort for at least 60 days. The start of the follow-up was defined as the first medical appointment at INI. The outcome of interest was the incidence of the first CVD during follow-up such that for those who developed incident CVD, follow-up ended on the day of the diagnosis. For those not presenting any CVD, follow-up ended on the death date, last clinical visit, last blood drawn or study closure (December 312,013), whichever occurred first. Patients with history of cardiovascular disease (CVD) prior to cohort enrollment $(n=59$ patients $)$ were excluded from the study population. Lost to follow-up (LTFU) was defined for patients known not to be deceased as not having a clinical visit (medical visit, CD4, HIV viral load) after January 12,013. Patients LTFU contributed to the follow-up time up to the date of last clinical visit.

\section{Study definitions}

We defined severe infections as any hospitalization related to any acute infection diagnosis (based on the discharge summary), which included ICD-10 codes for bacterial, viral, fungal or parasites infections (Additional file 1: Figure S1).

Cardiovascular diseases were defined as: coronary heart disease (CHD), stroke, peripheral arterial disease, deep venous thrombosis (DVT), pulmonary embolism, disorders of the heart muscle - cardiomyopathies - and disorders of the rhythm [23] (Additional file 2: Table S1). In cases when the CVD occurred during the hospitalization for infections, this hospitalization counted as an outcome (CVD) but not as an independent variable (severe infection). The following co-morbidities were defined up to patient's end of follow-up. Hepatitis B and C co-infections were defined as having a positive $\mathrm{HBsAg}$ antigen and by the presence of anti-HCV antibodies, respectively. Arterial hypertension was defined as use of antihypertensive medication, systolic blood pressure $>140 \mathrm{mmHg}$, or diastolic blood pressure $>90 \mathrm{mmHg}[15,24]$ prior to the end of follow-up. Diabetes was defined as use of diabetes mellitus pharmacological treatment or a fasting glucose level $\geq 126 \mathrm{mg} / \mathrm{dL}$ or a hemoglobin A1c value of 6.5 or greater $[15,25,26]$ prior to end of follow-up. Dyslipidemia was defined by the use of lipid-lowering therapy, low-density lipoprotein (LDL) cholesterol $>159 \mathrm{mg} / \mathrm{dL}$, high-density lipoprotein (HDL) cholesterol $<40 \mathrm{mg} / \mathrm{dL}$, total cholesterol $>239 \mathrm{mg} / \mathrm{dL}$, or triglycerides $>199 \mathrm{mg} /$ $\mathrm{dL}[15,27]$ prior to the end of follow-up. cART use was defined for those who had 60 days or more of exposure to at least three antiretroviral drugs: two nucleoside reverse transcriptase inhibitors and either one protease inhibitor, one non-nucleoside reverse transcriptase inhibitor or one integrase inhibitor. ART adherence information was not available such that ART use was presumed for the entire follow-up time for those meeting the criteria described above. Tobacco ever use and cocaine ever use (comprises inhaled, smoked and injection use) were defined based on self-report.

\section{Statistical methods}

Incidence rates of cardiovascular disease were calculated by dividing the number of events by the person-years at risk. Rates were calculated per 1000 person-years (PY) with respective 95\% confidence interval using Poisson regression model. To explore the effect of severe infections on the incidence of CVD we used extended Cox regression models. We stratified a patient's post-infection follow-up time into three periods as follows: $<3$ months post-hospitalization, 3-12 months post-hospitalization and more than a year post-hospitalization. Descriptive statistics for demographic and clinical variables were compared using Kruskal-Wallis test for continuous variables and chi-squared for categorical variables. CD4 nadir was defined as the lowest CD4 count value available for each patient. Last CD4 count, last CD4/CD8 ratio and last HIV-RNA were defined as the last results within the patient's final year of follow-up. Kaplan-Meier survival curves were plotted to show how the survival experience varied among groups. Beyond severe 
infections, other independent variables explored through unadjusted Cox regression models were age (as a time dependent variable), sex, race, HIV exposure category, educational level, hepatitis $\mathrm{B}$ and $\mathrm{C}$ co-infections, tobacco use, cocaine use, >arterial hypertension, diabetes, and dyslipidemia. The initial adjusted models included all variables explored in the unadjusted models that presented a $p$-value less than 0.20 . The final model was achieved through backwards elimination until only significant variables, at the $\mathrm{p}$-value of $<0.05$, were present. Random imputation for missing values in viral loads, CD4 counts, and CD4/ CD8 ratio was performed. Unadjusted and adjusted models without imputations for missing values were also fitted (Additional file 3: Table S2). R (version 3.0.3), library Survival were used for the analyses.

\section{Results}

Overall, 3475 HIV-infected individuals aged 18 years or more enrolled the INI cohort between January 12,000 and December 312,013. After excluding 59 HIV-infected individuals with past history of CVD and 32 who had no CD4+ cell count during follow-up, 3384 HIV-infected individuals were included in the present study (accounting for a total follow-up of 16,584 PY), with a median follow-up time of 4.4 years (interquartile range (IQR) 1.9-7.3 years). During the study period, 184 persons had CVD yielding an incidence rate of 11.10/1000 PY (95\%CI: 9.60-12.82), and 178 (5.3\%) individuals were lost to follow-up, yielding a rate of lost to follow-up of 10.73/1000 PY (95\% CI, 9.27-12.43) (Fig. 1). A complete list of ICD-10 codes for CVD included in this analysis is provided in the supplementary material (Additional file 2: Table S1).

At baseline, median age was 40.5 years (IQR, 33.1-48.4), $68.3 \%$ were male, $50.7 \%$ non-white, and $52 \%$ had more than 9 years of schooling (Table 1). Tobacco and cocaine use were reported in 65.8 and $7.9 \%$, respectively. The median nadir CD4+ count was 200 (IQR 71-325) cells/ $\mathrm{mm}^{3}$ and $86.4 \%$ used cART for at least 60 days before end of follow-up. Median time of cART use was 4.5 years (IQR 2.1-8.0). Among those who did not have a CVD, median time was 4.5 years (IQR 2.2-8.0), and among those who had a CVD, median time was 3.4 years (IQR 1.3-6.8). Sixty-five percent of participants had a viral load less than 400 copies $/ \mathrm{mL}$ in the year prior to their event/end of follow-up. Traditional CVD risk factors such as dyslipidemia, hypertension and diabetes mellitus were present in 46.3, 20.9 and $10 \%$ of all HIV-infected individuals, respectively, and were significantly more prevalent among participants with incident CVD.

In unadjusted analyses, non-white race/ethnicity, last HIV RNA $\geq 400$ copies/mL, hypertension and tobacco use were associated with increased risk of CVD. High last $\mathrm{CD} 4^{+}$count $(350-500$ and $\geq 500$ cells $/ \mathrm{mL})$ and high $\mathrm{CD}^{+} / \mathrm{CD}^{+}$ratio $(0.40-0.69$ and $\geq 0.7)$ were protective against CVD (Table 1). The Kaplan-Meier survival curve (Fig. 2) illustrates the probability of developing incident CVD over time for HIV-infected individuals who never

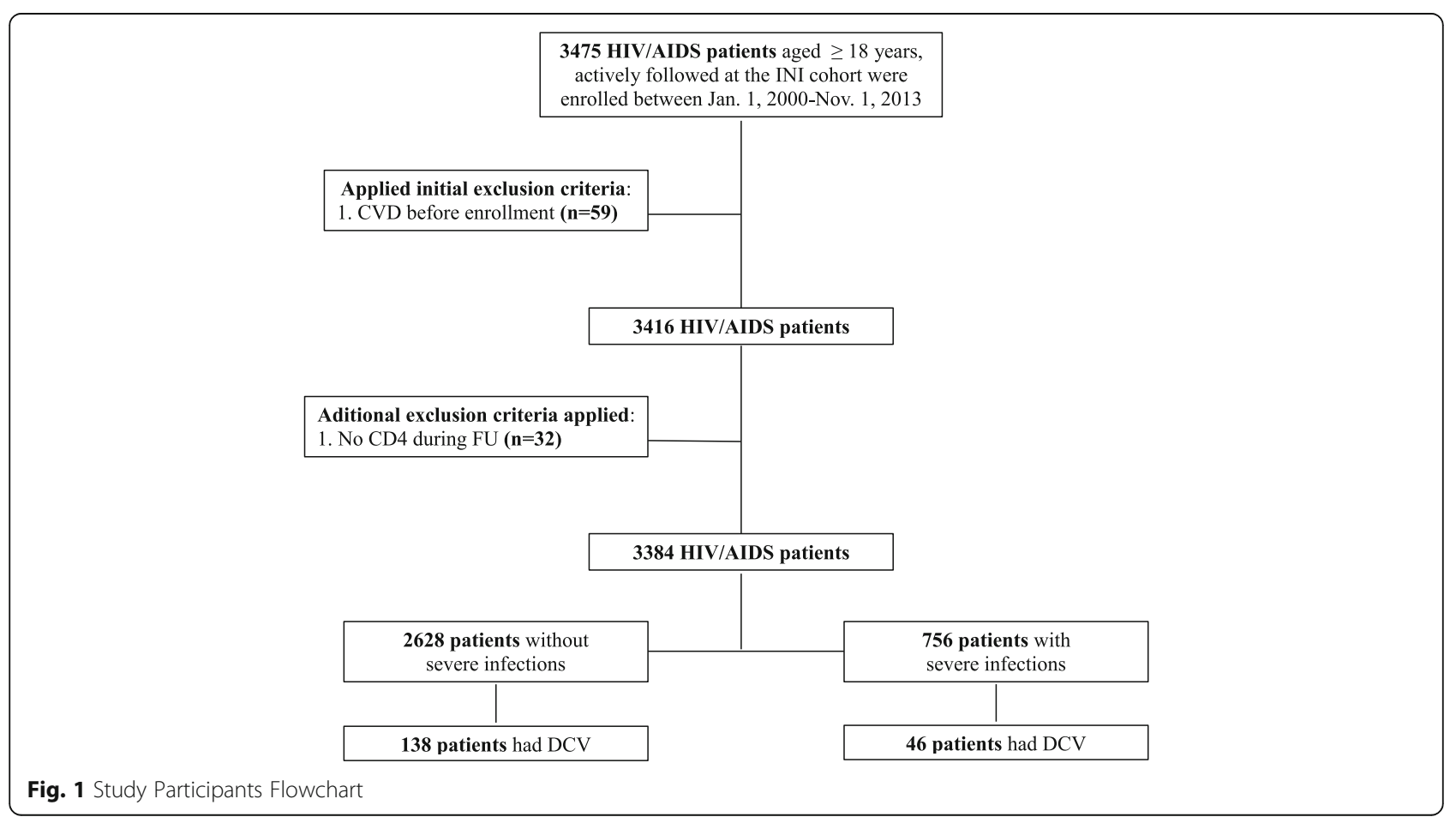


Table 1 Characteristics of the study population

\begin{tabular}{|c|c|c|c|c|}
\hline & $\begin{array}{l}\text { No CVD } \\
(N=3200 ; 16,029.2 \mathrm{PY})\end{array}$ & $\begin{array}{l}\text { Had CVD } \\
(N=184 ; 554.4 \mathrm{PY})\end{array}$ & $\begin{array}{l}\text { All patients } \\
(N=3384 ; 16,583.7 \mathrm{PY})\end{array}$ & $\begin{array}{l}\text { crude HR } \\
(95 \% \mathrm{Cl})\end{array}$ \\
\hline Median FU in years (IQR) & $4.5(2,7.3)$ & $2(0.6,4.3)$ & $4.4(1.9,7.3)$ & \\
\hline \multicolumn{5}{|l|}{ Sex } \\
\hline Male & $2180(68.1)$ & $130(70.7)$ & $2310(68.3)$ & ref. \\
\hline Female & $1018(31.8)$ & $56(29.9)$ & $1074(31.7)$ & $0.80(0.58,1.10)$ \\
\hline \multicolumn{5}{|l|}{ Age in years at end of FU } \\
\hline median (IQR) & $40.2(32.9,48.1)$ & $46.6(37.8,53.5)$ & $40.5(33.1,48.4)$ & \\
\hline$\leq 30(\%)$ & 409 (12.8) & $16(8.7)$ & $425(12.6)$ & ref. \\
\hline $31-45(\%)$ & $1692(52.9)$ & $64(34.8)$ & $1756(51.9)$ & $0.53(0.31,0.89)$ \\
\hline $46-59(\%)$ & $958(29.9)$ & $88(46.7)$ & $1044(30.9)$ & $0.97(0.58,1.61)$ \\
\hline$\geq 60(\%)$ & $141(4.4)$ & $18(9.8)$ & $159(4.7)$ & $1.34(0.69,2.60)$ \\
\hline \multicolumn{5}{|l|}{ Race/ethnicity } \\
\hline white (\%) & $1585(49.5)$ & $83(45.1)$ & $1668(49.3)$ & ref. \\
\hline non-white (\%) & $1615(50.5)$ & $101(54.9)$ & $1716(50.7)$ & $1.56(1.16,2.09)$ \\
\hline \multicolumn{5}{|l|}{ Educational level } \\
\hline up to 9 years (\%) & $1518(47.4)$ & $107(58.2)$ & $1625(48)$ & ref. \\
\hline more than 9 years (\%) & $1682(52.6)$ & $77(41.8)$ & $1759(52)$ & $0.67(0.50,0.90)$ \\
\hline \multicolumn{5}{|l|}{ CD4 nadir (cells/mm³) } \\
\hline median(IQR) & $204(71.8326 .2)$ & $140(53,306)$ & $200(71,325)$ & $1.03(0.93,1.13)$ \\
\hline$>350(\%)$ & $677(21.2)$ & $33(17.9)$ & $710(21)$ & - \\
\hline $201-350(\%)$ & $939(29.3)$ & $40(21.7)$ & $979(28.9)$ & - \\
\hline 51-200 (\%) & $960(30)$ & $68(37)$ & $1028(30.4)$ & - \\
\hline$\leq 50(\%)$ & $624(19.5)$ & $43(23.4)$ & $667(19.7)$ & - \\
\hline \multicolumn{5}{|l|}{ Last HIV RNAa (copies/mL) } \\
\hline$<400(\%)$ & $2116(66.1)$ & $108(58.7)$ & $2224(65.7)$ & ref. \\
\hline$\geq 400(\%)$ & $746(23.3)$ & $62(33.7)$ & $808(23.9)$ & $2.40(1.75,3.31)$ \\
\hline missing (\%) & $338(10.6)$ & $14(7.6)$ & $352(10.4)$ & - \\
\hline \multicolumn{5}{|l|}{ Last CD4a (cells/mm³) } \\
\hline median (IQR) & $544.5(341,741.2)$ & $397(222.5645 .5)$ & 537 (330.5739) & \\
\hline$<350(\%)$ & $765(23.9)$ & $80(43.5)$ & $845(25)$ & ref. \\
\hline 350-499 (\%) & $540(16.9)$ & $28(15.2)$ & $568(16.8)$ & $0.40(0.26,0.63)$ \\
\hline$\geq 500(\%)$ & $1663(52)$ & 71 (38.6) & $1734(51.2)$ & $0.27(0.19,0.37)$ \\
\hline missing (\%) & $232(7.2)$ & $5(2.7)$ & $237(7)$ & - \\
\hline \multicolumn{5}{|l|}{ Last CD4:CD8 ratioa } \\
\hline$<0.40(\%)$ & $865(27)$ & $79(42.9)$ & $944(27.9)$ & ref. \\
\hline $0.40-0.69(\%)$ & $894(27.9)$ & $46(25)$ & $940(27.8)$ & $0.49(0.34,0.69)$ \\
\hline$\geq 0.70(\%)$ & $1157(36.2)$ & $44(23.9)$ & $1201(35.5)$ & $0.33(0.23,0.47)$ \\
\hline missing (\%) & $708(22.1)$ & $21(11.4)$ & $729(21.5)$ & - \\
\hline ART use $\mathrm{e}^{\mathrm{b}}$ & 2781 (86.9) & $144(78.3)$ & $2925(86.4)$ & $0.26(0.18,0.38)$ \\
\hline Hypertension & $626(19.6)$ & $82(44.6)$ & $708(20.9)$ & $2.10(1.56,2.84)$ \\
\hline Diabetes & $311(9.7)$ & $28(15.2)$ & $339(10)$ & $1.23(0.81,1.86)$ \\
\hline Dyslipidemia & 1466 (45.8) & $101(54.9)$ & $1567(46.3)$ & $0.93(0.69,1.26)$ \\
\hline Tobacco $^{c}$ & $1802(56.3)$ & $117(63.6)$ & $1919(56.7)$ & $1.20(0.88,1.63)$ \\
\hline Cocaine $^{c}$ & $255(8)$ & $13(7.1)$ & $268(7.9)$ & $0.69(0.40,1.23)$ \\
\hline
\end{tabular}


Table 1 Characteristics of the study population (Continued)

\begin{tabular}{|c|c|c|c|c|}
\hline & $\begin{array}{l}\text { No CVD } \\
(N=3200 ; 16,029.2 \mathrm{PY})\end{array}$ & $\begin{array}{l}\text { Had CVD } \\
(N=184 ; 554.4 \mathrm{PY})\end{array}$ & $\begin{array}{l}\text { All patients } \\
(N=3384 ; 16,583.7 \mathrm{PY})\end{array}$ & $\begin{array}{l}\text { crude HR } \\
(95 \% \mathrm{Cl})\end{array}$ \\
\hline \multicolumn{5}{|l|}{ Severe infections } \\
\hline no severe infections & $2490(77.8)$ & $138(75)$ & $2628(77.7)$ & ref. \\
\hline$<3$ months post severe infections & $45(1.4)$ & $10(5.4)$ & $55(1.6)$ & $5.02(2.64,9.56)$ \\
\hline $3-12$ months post severe infections & $80(2.5)$ & $12(6.5)$ & $92(2.7)$ & $2.32(1.28,4.18)$ \\
\hline $12+$ months post severe infections & $585(18.3)$ & $24(13)$ & 609 (18) & $0.99(0.59,1.59)$ \\
\hline
\end{tabular}

CVD: cardiovascular disease; PY: persons-year; IQR: interquartile range; FU: follow-up; ART: antiretroviral therapy

aWithin the last year of follow-up

${ }^{b}$ Defined as those who had 60 days or more of exposure to at least three antiretroviral drugs

${ }^{\mathrm{c}}$ Ever use

had severe infections and for those who had severe infections and developed incident CVD $<3$ months, 3-12 months, and $>12$ months post discharge.

In the adjusted analysis, non-white race/ethnicity (adjusted hazard ratio $(\mathrm{aHR}) 1.49, p$-value $=0.009)$, age $\geq 60$ years $(\mathrm{aHR} 2.01, \mathrm{p}$-value $=0.045)$ and hypertension $(\mathrm{aHR}$ 1.90 , p-value $<0.001$ ) were associated with an increased hazard of CVD events, while high CD4 counts $(\geq 500$ cells $/ \mathrm{mm}^{3}$ : aHR: 0.41 , p-value $<0.001$ ), cART use (aHR 0.21 , p-value $<0.001$ ) reduced the hazards of CVD events. Also, high $\mathrm{CD} 4+/ \mathrm{CD} 8+$ ratio borderline reduced the risk of CVD ( $\geq 0.7$, aHR 0.66, p-value = 0.062) (Fig. 3).

Severe infections during follow-up was strongly associated with incident CVD (Fig. 3), greatly increasing the risk of CVD $<3$ months post discharge (aHR 4.52, 95\% CI 2.46-8.30) and 3-12 months post discharge (aHR 2.39, 95\% CI 1.30-4.38). Similar effects were observed in the models without imputation for missing values in viral load, $\mathrm{CD} 4$, and, $\mathrm{CD} 4+/ \mathrm{CD} 8+$ ratio (Additional file 3: Table S2).

\section{Discussion}

In this study, we investigated the association between hospitalization for severe infection and subsequent risk of CVD in a large, well-characterized cohort of HIV-infected individuals in a middle-income country. We demonstrate that, after controlling for traditional and HIV-related CVD risk factors, the presence of severe infection is associated with an increase in CVD risk in the year following hospital discharge. Moreover, we observed that this association is time-dependent, higher within the first 3 months post hospital discharge (4-fold). These results is in accordance with data from the general population. For instance, Corrales-Medina and colleagues demonstrated that the association between hospital admission for pneumonia and subsequent risk

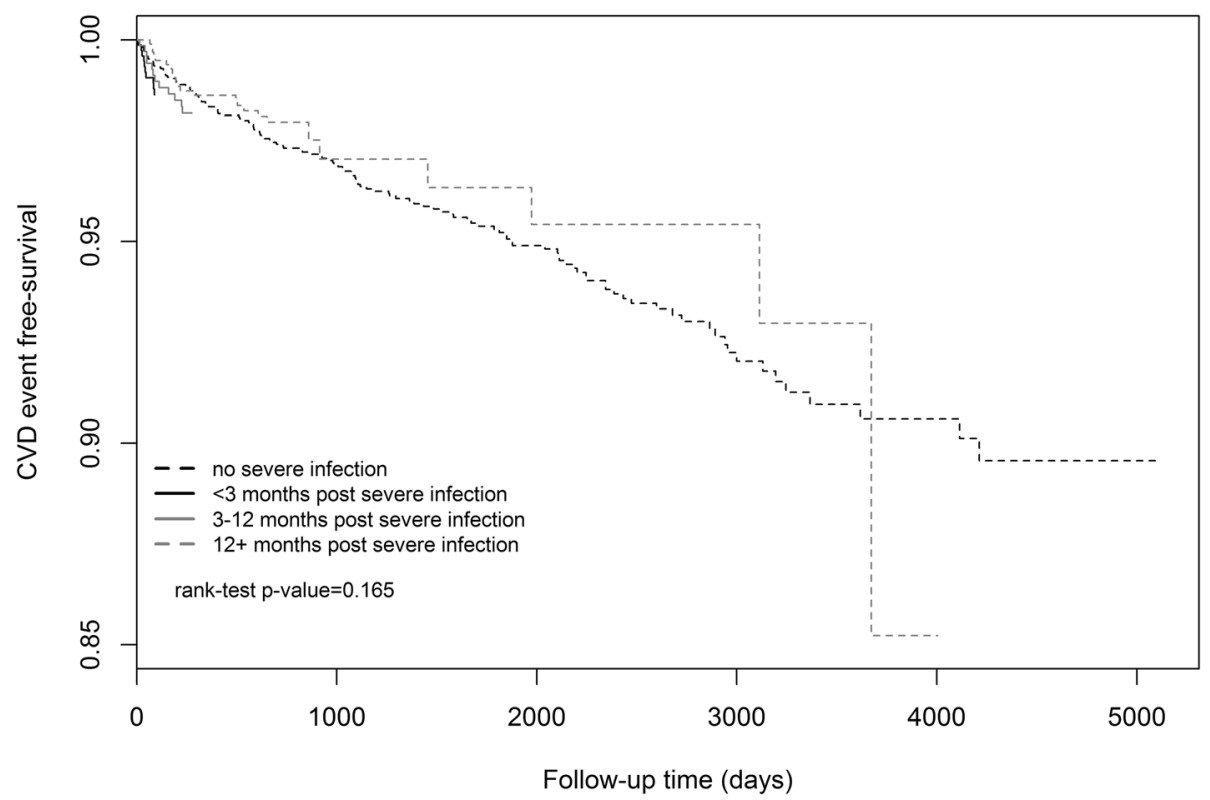

Fig. 2 Kaplan-Meier survival curve illustrating the probability of CVD over follow-up time for patients with no severe infection and with severe infection: < 3 months post hospital discharge; 3-12 months post hospital discharge; > 12 months hospital discharge 


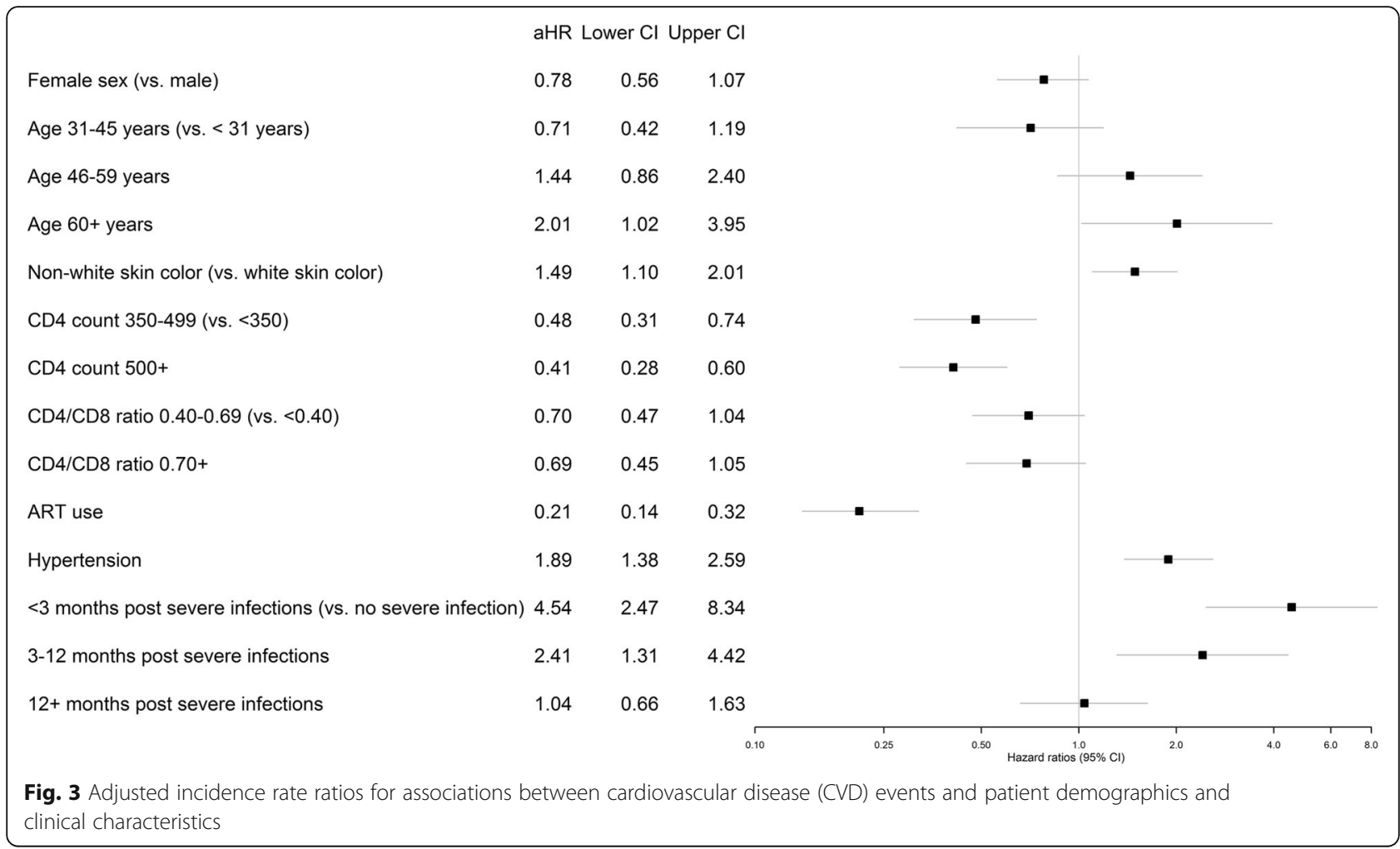

of CVD is time-dependent and remains significant up to 10 years after hospital discharge [28]. In fact, hospitalization for infections is associated with an inflammatory state and a pro-coagulant activity that can persist long after infection resolves [29, 30].

Another strength of our study is the characterization of a protective effect of cART use, and high CD4 counts (>500), on the CVD risk of HIV-infected individuals who survive hospitalization for severe infection. This data helps to build the body of evidence of an overall benefit of cART use on CVD risk [10, 31, 32]. cART is able to attenuate inflammation and endothelial dysfunction among HIV-infected individuals [32-34], factors considered to play a key role in the increased CVD risk of this population [35-41]. We have also observed a borderline association between reduced hazard of CVD events and high CD4+/CD8+ ratio ( $\geq 0.7)$, a marker of increased innate and adaptive immune activation, and higher risk of morbidity [42, 43]. This data, together with the protective effect of high CD4+ counts aforementioned, is in accordance with previous data from our group and others, demonstrating a protective effect of virologic suppression and preservation of CD4+ counts on incident CVD $[8,15]$.

The role of acute infection as short-term risk of CVD have been explored in the general population [28, 4448]. Similarly, our results suggests that a past medical history of hospital admission for severe infection (at least in the past year) should be part of the clinical assessment of cardiovascular risk performed by HIV/ AIDS caregivers.

There are limitations to the current study that deserve mention. Its observational design limited our ability to control for unknown sources of confounding and bias. We only captured hospitalizations at the INI hospital, which could underestimate severe infections and CVD incidences in this cohort. However, as INI is the referral center for HIV-infected individuals experiencing serious hospitalizations, missing data due to hospitalizations outside INI were likely minimized. We were not able to classify AMI into specific types [49], which could have helped to better understand the underlying mechanism of ischemia in this population. Prior data suggests a higher prevalence of type 2 AMI among HIV-infected individuals [50]. We could not fully account for the effects of chronic kidney disease as time updated glomerular filtration rates were not available. Dyslipidemia definition is dynamic and has recently been updated [51]. However, our definition is in accordance with recent publications $[28,52]$ and is able to capture moderate and severe cases of dyslipidemia. Moreover, dyslipidemia was not associated with CVD in our study. Important strengths of this study include the well-characterized nature of this cohort, its diversity of race and sex, and the characterization of acute CVD events beyond myocardial infarctions. 


\section{Conclusions}

We provide evidence for a time-dependent association between severe infection and incident cardiovascular disease in HIV-infected individuals from a large, clinical cohort in a middle-income country. cART use, and high CD4 count were significantly associated with reduced hazards of CVD, thus strengthening the body of evidence towards of an overall benefit of cART use on CVD risk in this population.

\section{Additional files}

Additional file 1: Figure S1. Severe infections by etiology. Number of severe infections in each category, i.e. AIDS-related, bacterial, viral, fungal, or parasitic. (DOCX $25 \mathrm{~kb}$ )

Additional file 2: Table S1. Incident cardiovascular diseases among HIV/AIDS patients during follow-up. Complete list of ICD-10 codes for cardiovascular diseases and its frequency in the study. (DOCX 14 kb)

Additional file 3: Table S2. Unadjusted and adjusted extended time dependent Cox regression models (with no imputations for missing values in viral load, CD4 and CD4/CD8 ratio). This is the unadjusted and adjusted extended time dependent Cox regression models (with no imputations for missing values in viral load, CD4 and CD4/CD8 ratio). (DOCX $19 \mathrm{~kb}$ )

\section{Abbreviations}

aHR: Adjusted hazard ratio; AIDS: Acquired Immune Deficiency Syndrome; AMI: Acute myocardial infarction; CART: Combined antiretroviral therapy; CHD: Coronary heart disease; CHR: Crude hazard ratio; CVD: Cardiovascular disease; CVDs: Cardiovascular diseases; DVT: Deep venous thrombosis; HIV: Human immunodeficiency virus; ICD-10: International Statistical Classification of Diseases and Related Health Problems; LTFU: Lost to follow-up; NCD: Noncommunicable diseases; PY: Person-year; TCD4 +: CD4+ Thelper cells; TCD8 + : CD8+ T cells

\section{Acknowledgements}

We gratefully acknowledge the patients who made this study possible.

\section{Funding}

This work was supported by grants from Conselho Nacional de Desenvolvimento Científico e Tecnológico (CNPq), Fundação de Amparo a Pesquisa do Estado do Rio de Janeiro (FAPERJ), and Programa Estratégico de Apoio à Pesquisa em Saúde (PAPES)/Fiocruz.

\section{Availability of data and materials}

The datasets generated and/or analyzed during the current study are not publicly available but could be available from the corresponding author on reasonable request.

\section{Authors' contributions}

ECM and LEC conceived of the study, participated in its design, managed the data, conducted the statistical analyses and drafted the manuscript. FAB, PML, BG and VGV conceived of the study and participated in its design and coordination. RTA helped with literature review and drafting of the manuscript. All authors have given final approval of the version to be published and agree to be accountable for all aspects of the work in ensuring that questions related to the accuracy or integrity of any part of the work are appropriately investigated and resolved.

\section{Ethics approval and consent to participate}

This study was approved by the ethics committee of the INI (CAAE 0032.0.009.00010) and was conducted according to the principles expressed in the Declaration of Helsinki. All patient records/information was de-identified prior to analysis.

\section{Consent for publication}

Not applicable.

\section{Competing interests}

The authors declare no financial or non-financial competing interests.

\section{Publisher's Note}

Springer Nature remains neutral with regard to jurisdictional claims in published maps and institutional affiliations.

\section{Author details}

${ }^{1}$ Laboratório de Pesquisa Clínica em Medicina Intensiva, Instituto Nacional de Infectologia Evandro Chagas (INI), Fundação Oswaldo Cruz (FIOCRUZ), Rio de Janeiro, Brazil. ${ }^{2}$ Laboratório de HIV, Instituto de Nacional de Infectologia Evandro Chagas (INI), Fundação Oswaldo Cruz (FIOCRUZ), Rio de Janeiro, Brazil. ${ }^{3}$ Instituto D'Or de Pesquisa e Ensino (IDOR), Rio de Janeiro, Brazil.

Received: 27 June 2018 Accepted: 11 March 2019

Published online: 11 April 2019

References

1. Antiretroviral Therapy Cohort Collaboration. Causes of Death in HIV-1Infected Patients Treated with Antiretroviral Therapy, 1996-2006: Collaborative Analysis of 13 HIV Cohort Studies. Clin Infect Dis. 2010;50: 1387-96.

2. Pacheco AG, Tuboi SH, Faulhaber JC, Harrison LH, Schechter M. Increase in Non-AIDS Related Conditions as Causes of Death among HIV-Infected Individuals in the HAART Era in Brazil. PLoS One. 2008;3:e1531.

3. Grinsztejn B, Luz PM, Pacheco AG, Santos DVG, Velasque L, Moreira RI, et al. Changing Mortality Profile among HIV-Infected Patients in Rio de Janeiro, Brazil: Shifting from AIDS to Non-AIDS Related Conditions in the HAART Era. PLoS One. 2013:8:e59768.

4. Freiberg MS, Chang C-CH, Kuller LH, Skanderson M, Lowy E, Kraemer KL, et al. HIV Infection and the Risk of Acute Myocardial Infarction. JAMA Intern Med. 2013;173:614.

5. Sico JJ, Chang C-CH, So-Armah K, Justice AC, Hylek E, Skanderson M, et al. HIV status and the risk of ischemic stroke among men. Neurology. 2015;84: 1933-40.

6. Butt AA, Chang C-C, Kuller L, Goetz MB, Leaf D, Rimland D, et al. Risk of heart failure with human immunodeficiency virus in the absence of prior diagnosis of coronary heart disease. Arch Intern Med. 2011;171:737-43.

7. Tseng ZH, Secemsky EA, Dowdy D, Vittinghoff E, Moyers B, Wong JK, et al. Sudden cardiac death in patients with human immunodeficiency virus infection. J Am Coll Cardiol. 2012;59:1891-6.

8. Triant VA, Lee H, Hadigan C, Grinspoon SK. Increased Acute Myocardial Infarction Rates and Cardiovascular Risk Factors among Patients with Human Immunodeficiency Virus Disease. J Clin Endocrinol Metab. 2007;92: 2506-12.

9. Savès $M$, Chêne $G$, Ducimetière $P$, Leport $C$, Le Moal $G$, Amouyel $P$, et al. Risk factors for coronary heart disease in patients treated for human immunodeficiency virus infection compared with the general population. Clin Infect Dis. 2003;37:292-8

10. Lang S, Mary-Krause M, Simon A, Partisani M, Gilquin J, Cotte L, et al. HIV Replication and Immune Status Are Independent Predictors of the Risk of Myocardial Infarction in HIV-Infected Individuals. Clin Infect Dis. 2012;55: 600-7.

11. Paisible A-L, Chang C-CH, So-Armah KA, Butt AA, Leaf DA, Budoff M, et al. HIV Infection, Cardiovascular Disease Risk Factor Profile, and Risk for Acute Myocardial Infarction. JAIDS J Acquir Immune Defic Syndr. 2015;68:209-16.

12. Young J, Xiao Y, Moodie EEM, Abrahamowicz M, Klein MB, Bernasconi E, et al. Effect of Cumulating Exposure to Abacavir on the Risk of Cardiovascular Disease Events in Patients From the Swiss HIV Cohort Study. J Acquir Immune Defic Syndr 1999. 2015;69:413-21.

13. DAD Study Group, Friis-Møller N, Reiss P, Sabin CA, Weber R, d'Arminio MA, et al. Class of antiretroviral drugs and the risk of myocardial infarction. N Engl J Med. 2007;356:1723-35.

14. Stein $\mathrm{JH}$, Hsue PY. Inflammation, immune activation, and CVD risk in individuals with HIV infection. JAMA. 2012;308:405-6.

15. Diaz CM, Segura ER, Luz PM, Clark JL, Ribeiro SR, De Boni R, et al. Traditional and HIV-specific risk factors for cardiovascular morbidity and mortality among HIV-infected adults in Brazil: a retrospective cohort study. BMC Infect Dis. 2016;16. https://doi.org/10.1186/s12879-016-1735-4.

16. Deeks SG, Lewin SR, Havlir DV. The end of AIDS: HIV infection as a chronic disease. The Lancet. 2013;382:1525-33. 
17. Huang L, Quartin A, Jones D, Havlir DV. Intensive care of patients with HIV infection. N Engl J Med. 2006;355:173-81.

18. Japiassú AM, Amâncio RT, Mesquita EC, Medeiros DM, Bernal HB, Nunes EP, et al. Sepsis is a major determinant of outcome in critically ill HIV/AIDS patients. Crit Care. 2010;14:R152.

19. Greenberg JA, Lennox JL, Martin GS. Outcomes for critically ill patients with HIV and severe sepsis in the era of highly active antiretroviral therapy. J Crit Care. 2012;27:51-7.

20. Amancio RT, Japiassu AM, Gomes RN, Mesquita EC, Assis EF, Medeiros DM, et al. The innate immune response in HIV/AIDS septic shock patients: a comparative study. PLoS One. 2013;8:e68730.

21. Grinsztejn B, Veloso VG, Friedman RK, Moreira RI, Luz PM, Campos DP, et al. Early mortality and cause of deaths in patients using HAART in Brazil and the United States. AIDS Lond Engl. 2009;23:2107-14.

22. Ribeiro SR, Luz PM, Campos DP, Moreira Rl, Coelho L, Japiassu A, et al. Incidence and determinants of severe morbidity among HIV-infected patients from Rio de Janeiro, Brazil, 2000-2010. Antivir Ther. 2014;19:387-97.

23. $\mathrm{WHO} \mid$ Cardiovascular diseases (CVDs). WHO. http://www.who.int/ mediacentre/factsheets/fs317/en/. Accessed 10 Sep 2016

24. Williams B, Mancia G, Spiering W, Agabiti Rosei E, Azizi M, Burnier M, et al. 2018 ESC/ESH Guidelines for the management of arterial hypertension. Eur Heart J. 2018;39:3021-104.

25. WHO. Use of Glycated Haemoglobin (HbA1c) in the Diagnosis of Diabetes Mellitus: Abbreviated Report of a WHO Consultation. Geneva: World Health Organization; 2011. http://www.ncbi.nlm.nih.gov/books/NBK304267/. Accessed 8 Feb 2019.

26. Basevi V, Di Mario S, Morciano C, Nonino F, Magrini N. Comment on: American Diabetes Association. Standards of Medical Care in Diabetes-2011. Diabetes Care. 2011;34(Suppl. 1):S11-61 Diabetes Care. 2011;34:e53.

27. Bakal DR, Coelho LE, Luz PM, Clark JL, De Boni RB, Cardoso SW, et al. Obesity following ART initiation is common and influenced by both traditional and HIV-/ART-specific risk factors. J Antimicrob Chemother. 2018; 73:2177-85.

28. Corrales-Medina VF, Alvarez KN, Weissfeld LA, Angus DC, Chirinos JA, Chang $\mathrm{C}-\mathrm{CH}$, et al. Association Between Hospitalization for Pneumonia and Subsequent Risk of Cardiovascular Disease. JAMA. 2015;313:264.

29. Yende S, D'Angelo G, Kellum JA, Weissfeld L, Fine J, Welch RD, et al. Inflammatory Markers at Hospital Discharge Predict Subsequent Mortality after Pneumonia and Sepsis. Am J Respir Crit Care Med. 2008;177:1242-7.

30. Yende S, D'Angelo G, Mayr F, Kellum JA, Weissfeld L, Kaynar AM, et al. Elevated Hemostasis Markers after Pneumonia Increases One-Year Risk of All-Cause and Cardiovascular Deaths. PLoS One. 2011;6:e22847.

31. Phillips AN, Carr A, Neuhaus J, Visnegarwala F, Prineas R, Burman WJ, et al. Interruption of antiretroviral therapy and risk of cardiovascular disease in persons with HIV-1 infection: exploratory analyses from the SMART trial. Antivir Ther. 2008:13:177-87.

32. Torriani FJ, Komarow L, Parker RA, Cotter BR, Currier JS, Dubé MP, et al. Endothelial Function in Human Immunodeficiency Virus-Infected Antiretroviral-Naive Subjects Before and After Starting Potent Antiretroviral Therapy. J Am Coll Cardiol. 2008;52:569-76.

33. Baker JV, Neuhaus J, Duprez D, Freiberg M, Bernardino J, Badley AD, et al. HIV Replication, Inflammation, and the Effect of Starting Antiretroviral Therapy on Plasma Asymmetric Dimethylarginine, a Novel Marker of Endothelial Dysfunction. J Acquir Immune Defic Syndr 1999. 2012;60:128.

34. Bernal E, Saban J. Hyper-inflammation and Endothelial Activation in HIV Infected Patients with Detectable and Undetectable Viral Load. J AIDS Clin Res. 2012;03. https://doi.org/10.4172/2155-6113.1000164.

35. Falasca K, Ucciferri C, Mancino P, Di lorio A, Vignale F, Pizzigallo E, et al. Cystatin C, adipokines and cardiovascular risk in HIV infected patients. Curr HIV Res. 2010;8:405-10

36. Kalayjian RC, Machekano RN, Rizk N, Robbins GK, Gandhi RT, Rodriguez BA, et al. Pretreatment levels of soluble cellular receptors and interleukin-6 are associated with HIV disease progression in subjects treated with highly active antiretroviral therapy. J Infect Dis. 2010;201:1796-805.

37. Armah KA, McGinnis K, Baker J, Gibert C, Butt AA, Bryant KJ, et al. HIV status, burden of comorbid disease, and biomarkers of inflammation, altered coagulation, and monocyte activation. Clin Infect Dis Off Publ Infect Dis Soc Am. 2012;55:126-36.

38. Subramanian S, Tawakol A, Burdo TH, Abbara S, Wei J, Vijayakumar J, et al. Arterial inflammation in patients with HIV. JAMA. 2012;308:379-86.
39. Grund B, Baker JV, Deeks SG, Wolfson J, Wentworth D, Cozzi-Lepri A, et al. Relevance of Interleukin-6 and D-Dimer for Serious Non-AIDS Morbidity and Death among HIV-Positive Adults on Suppressive Antiretroviral Therapy. PLoS One. 2016;11:e0155100.

40. Ucciferri C, Falasca K, Vecchiet J. Hypertension in HIV: Management and Treatment. AIDS Rev. 2017;19:198-211.

41. Mesquita EC, Hottz ED, Amancio RT, Carneiro AB, Palhinha L, Coelho LE, et al. Persistent platelet activation and apoptosis in virologically suppressed HIV-infected individuals. Sci Rep. 2018;8. https://doi.org/10.1038/s41598-01833403-0.

42. Lu W, Mehraj V, Vyboh K, Cao W, Li T, Routy J-P. CD4:CD8 ratio as a frontier marker for clinical outcome, immune dysfunction and viral reservoir size in virologically suppressed HIV-positive patients. J Int AIDS Soc. 2015;18. https://doi.org/10.7448/IAS.18.1.20052.

43. Serrano-Villar S, Sainz T, Lee SA, Hunt PW, Sinclair E, Shacklett BL, et al. HIVInfected Individuals with Low CD4/CD8 Ratio despite Effective Antiretroviral Therapy Exhibit Altered T Cell Subsets, Heightened CD8+ T Cell Activation, and Increased Risk of Non-AIDS Morbidity and Mortality. PLoS Pathog. 2014; 10:e1004078.

44. Corrales-Medina VF, Madjid M, Musher DM. Role of acute infection in triggering acute coronary syndromes. Lancet Infect Dis. 2010;10:83-92.

45. Ramirez J, Aliberti S, Mirsaeidi M, Peyrani P, Filardo G, Amir A, et al. Acute Myocardial Infarction in Hospitalized Patients with Community-Acquired Pneumonia. Clin Infect Dis. 2008;47:182-7.

46. Ludwig A, Lucero-Obusan C, Schirmer P, Winston C, Holodniy M. Acute cardiac injury events $\leq 30$ days after laboratory-confirmed influenza virus infection among U.S. veterans, 2010-2012. BMC Cardiovasc Disord. 2015;15. https://doi.org/10.1186/s12872-015-0095-0.

47. Smeeth L, Thomas SL, Hall AJ, Hubbard R, Farrington P, Vallance P. Risk of myocardial infarction and stroke after acute infection or vaccination. $\mathrm{N}$ Engl J Med. 2004;351:2611-8.

48. Baylin A, Hernandez-Diaz S, Siles X, Kabagambe EK, Campos H. Triggers of Nonfatal Myocardial Infarction in Costa Rica: Heavy Physical Exertion, Sexual Activity, and Infection. Ann Epidemiol. 2007;17:112-8.

49. Thygesen K, Alpert JS, White HD, on behalf of the Joint ESC/ACCF/AHA WHF Task Force for the Redefinition of Myocardial Infarction, TASK FORCE MEMBERS. Universal Definition of Myocardial Infarction. Circulation. 2007; 116:2634-53.

50. Crane HM, Paramsothy P, Drozd DR, Nance RM, Delaney JAC, Heckbert SR, et al. Types of Myocardial Infarction Among Human Immunodeficiency Virus-Infected Individuals in the United States. JAMA Cardiol. 2017;2:260.

51. Grundy SM, Stone NJ, Bailey AL, Beam C, Birtcher KK, Blumenthal RS, et al. 2018 AHA/ACC/AACVPR/AAPA/ABC/ACPM/ADA/AGS/APhA/ASPC/NLA/ PCNA Guideline on the Management of Blood Cholesterol: A Report of the American College of Cardiology/American Heart Association Task Force on Clinical Practice Guidelines. J Am Coll Cardiol. 2018. https://doi.org/10.1016/ j.jacc.2018.11.003.

52. Oliveira RVC, Shimakura SE, Campos DP, Hökerberg YHM, Victoriano FP Ribeiro S, et al. Effects of antiretroviral treatment and nadir CD4 count in progression to cardiovascular events and related comorbidities in an HIV Brazilian cohort: a multi-stage approach. AIDS Care. 2018;30:551-9.

Ready to submit your research? Choose BMC and benefit from:

- fast, convenient online submission

- thorough peer review by experienced researchers in your field

- rapid publication on acceptance

- support for research data, including large and complex data types

- gold Open Access which fosters wider collaboration and increased citations

- maximum visibility for your research: over $100 \mathrm{M}$ website views per year

At $\mathrm{BMC}$, research is always in progress.

Learn more biomedcentral.com/submissions 